
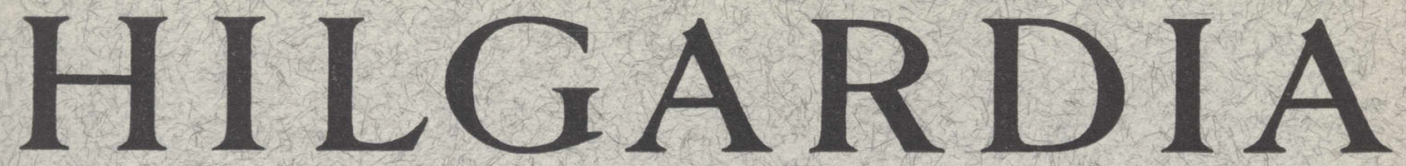

A Journal of Agricultural Science Published by the California Agricultural Experiment Station

\title{
CONTRASTING EFFECTS OF ACID AND NONACID PUMMELOS ON THE ACIDITY OF HYBRID CITRUS PROGENIES
}

ROBERT K. SOOST and JAMES W. CAMERON

CHANDLER-AN EARLY-RIPENING HYBRID PUMMELO DERIVED FROM A LOW-ACID PARENT

JAMES W. CAMERON and ROBERT K. SOOST 


\title{
CHANDLER-AN EARLY-RIPENING HYBRID PUMMELO DERIVED FROM A LOW-ACID PARENT'
}

\author{
JAMES W. CAMERON ${ }^{2}$ and ROBERT K. SOOST
}

\section{INTRODUCTION}

The Pummelo (Citrus grandis Osbeck) is a citrus species which is widely grown and used as a fresh fruit in southeast Asia, but is little known in the United States. Many varieties exist, partly because pummelos produce only sexual progeny and each new seedling is likely to be somewhat different from the next.

Pummelos and pummelo culture have been described by Wester (1917) ${ }^{\star}$ in the Philippine Islands, Reinking and Groff (1921) and Groff $(1927,1930)$ in Thailand, and Ochse (1931) in the Dutch East Indies. Reasoner (1888) discussed some varieties of pummelo growing in Florida. Swingle (1943) and Webber (1943) have discussed the botany and some of the cultivated varieties of the pummelo.

Among citrus fruits, the grapefruit is the closest relative of the pummelo. The two are similar in many respects, but the pummelo fruit is larger and has firmer flesh. In most varieties, it also has a considerably thicker rind. It often lacks the bitterness characteristic of grapefruit, although some pummelo varieties have highly unpleasant flavors. At Riverside, pummelos ripen earlier than grapefruit. In the Orient, the pummelo flesh apparently develops greater firmness than in California, and the juice vesicles can be eaten out of hand, even after removal of the segment membranes.

At the University of California Citrus Experiment Station, Riverside, a collection of some fifty pummelo varieties, mostly obtained through the United States Department of Agriculture, Bureau of Plant Introduction, has been maintained since about 1932. Under Riverside climatic conditions, most of these varieties have not been particularly promising. A few become good-flavored by March or April, some eleven months after flowering, but nearly all show severe fruit drop by that time, particularly during periods of high winds, which usually occur one or more times during the winter season. All the varieties have contained many seeds in the mixed plantings at the station, although in southeast Asia, fruits with few seeds are produced under some conditions.

In the United States, the seediness and firmness of the pummelo reduce its suitability for eating by halves with a spoon, as grapefruit are eaten. Likewise, it is not suitable for juicing. It serves best as a specialty fruit, to be eaten by slices out of hand, in salads, or fruit cups. By cutting pie-shaped or tangential sections, one can largely avoid the seeds and core. Unlike most

\footnotetext{
${ }^{1}$ Paper No. 1233, University of California Citrus Experiment Station, Riverside. Received for publ'cation December 16, 1959.

${ }^{2}$ Geneticist in the Agricultural Experiment Station, Riverside.

${ }^{8}$ Associate Geneticist in the Agricultural Experiment Station, Riverside.

"See "Literature Cited" for citations, referred to in the text by author and date.
} 

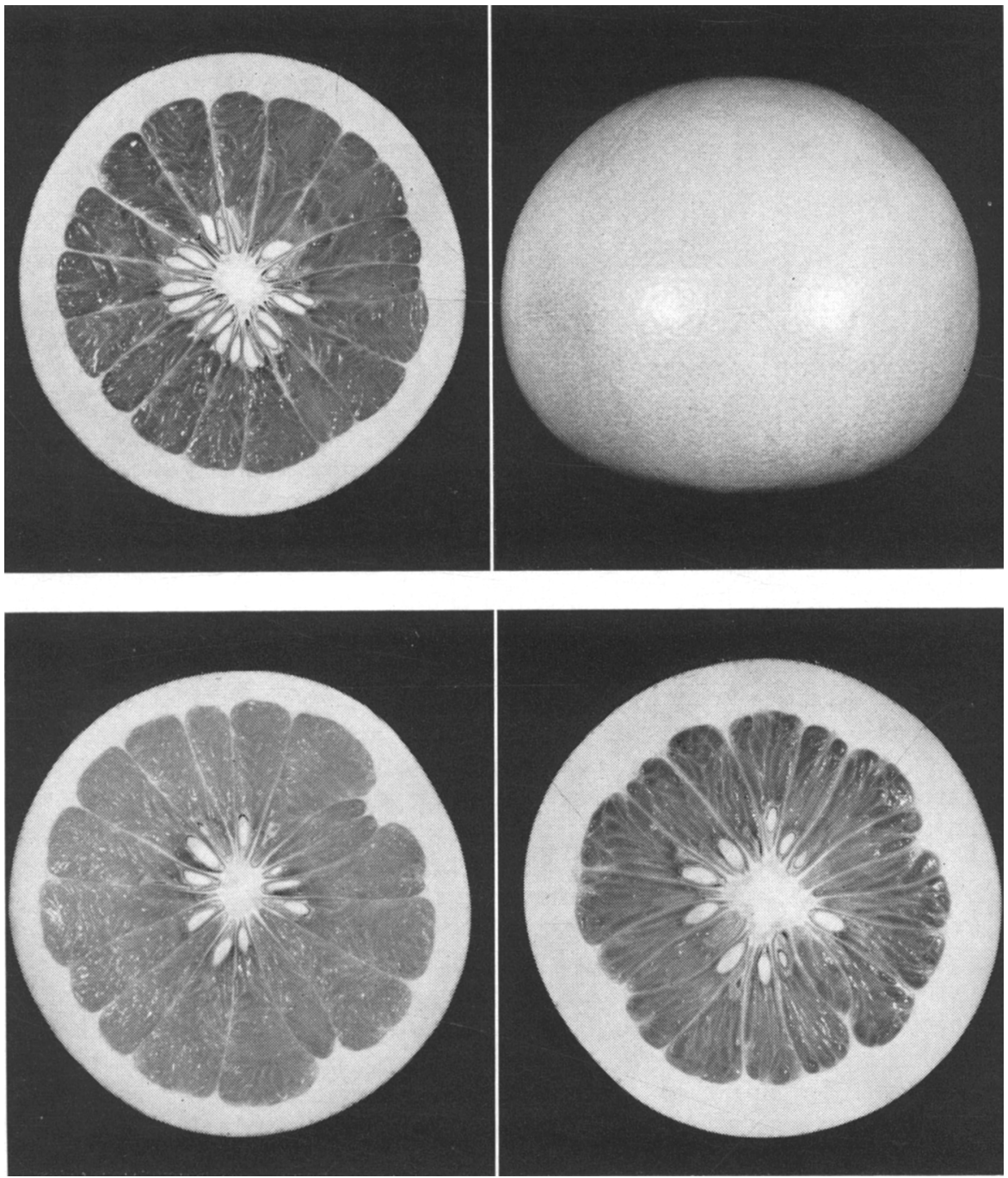

Fig. 1. (Top). The hybrid pummelo, Chandler. The fruit is slightly flattened globose, with a pale yellow rind, and has a mild, sweet flavor. About two-fifths natural size.

Fig. 2. (Bottom). Fruits of the parents of the hybrid. Left, low-acid pummelo 2240 ; right, pummelo 2241. The hybrid combines several of the better characters of the parents. 
citrus fruits, pummelos can often lie on the ground for many days without decaying. They also store well, showing little shriveling or loss of freshness.

\section{PARENTAGE OF THE HYBRID}

In 1945, extensive hybridization involving pummelos was carried out at the University of California Citrus Experiment Station under the direction of Dr. H. B. Frost and Dr. J. W. Lesley, Soost and Cameron (1961) (in this issue of Hilgardia) discuss some of these pummelos and their progenies, with respect to inheritance of levels of acidity and soluble solids. Among the progenies were a few from pummelo $\times$ pummelo, including the hybrid which is the subject of this paper. The seed parent of this hybrid bears fruit which has a medium level of soluble solids, but is essentially acidless. This pummelo is Citrus Experiment Station (C.E.S.) Accession Number 2240, and was received in 1930 under United States Department of Agriculture Plant Introduction Number CPB 10126. It has behaved as a dwarf at Riverside, on bitter-sweet orange rootstock. The fruit has no red coloration. The pollen parent (C.E.S. 2241, U.S.D.A. No. 10127) was one of several introductions (not all alike) which have carried the name "Kao Pan." It shows slight interior pink coloration, varying in amount from year to year.

\section{CHARACTERISTICS OF THE HYBRID AND ITS PARENTS}

Fruit of the new hybrid pummelo is shown in figure 1, at about two-fifths natural size. Cross sections of the fruits of the parents are shown in figure 2. The hybrid ripens at Riverside in December, nearly two months earlier than most of the presently established older varieties. It is of medium size (four and one-half to six inches in diameter), of flattened-globose shape, and has a smooth to grained rind. The rind is pale yellow and of medium thickness for a pummelo, varying from ten to twelve $\mathrm{mm}$. The flesh is pale yellow, with varying amounts of pink in portions of the segment membranes and juice vesicle membranes. As with other pigmented pummelos and pigmented grapefruits, this pink color is not present in the juice. At Riverside, it varies in intensity from year to year. However, in the six years during which the hybrid has been studied, its fruit has never failed to show some pink in cross section.

Table 1 shows juice analyses of fruit of the hybrid and of its parents over a three-year period. The hybrid has a moderate level of soluble solids and a moderate to slightly low percentage of acid, resulting in a mild, sweettasting fruit. There is no bitterness in the juice vesicles and only a trace in the albedo. Levels of soluble solids are generally similar to those of both parents, while the acidity is intermediate between that of the very low-acid 2240 and the rather high-acid 2241. This behavior follows the general pattern found in progenies of which pummelo 2240 was a parent (Soost and Cameron, 1961, in this issue). The solids : acid ratios of the hybrid have been higher than 11:1 throughout each season; in the very warm winter of 1958-1959, the ratio reached $16.4: 1$ by December 11. Neither of the parents has had satisfactory ratios, except parent 2241 in the 1958-1959 winter. 
Several of the desirable characteristies of the parents have been combined in the Chandler. It has a thinner rind, smaller core, thinner segment membranes, and a finer flesh texture than pummelo 2241 (see figs. 1 and 2). It averages a higher degree of pink in the flesh than does 2241 (2240 has none). It ripens earlier than 2241 and has a better over-all flavor than either parent. Since pummelo 2240 contains essentially no acid at maturity, this parent can hardly be compared to the hybrid for palatability, and would not be acceptable to most consumers in the United States.

Like its parents, and like the other pummelo varieties, the hybrid has many seeds. This may be partly due to climatic effects or to pollination by other citrus varieties. Experiments are under way to determine whether seediness in pummelos can be influenced by the source of pollen.

TABLE 1

JUICE COMPOSITION OF THE HYBRID PUMMELO, CHANDLER, AND ITS PUMMELO PARENTS, OVER A THREE-YEAR PERIOD

\begin{tabular}{|c|c|c|c|c|c|c|c|c|c|}
\hline \multirow{3}{*}{$\begin{array}{l}\text { Seasons and } \\
\text { sampling } \\
\text { dates* }\end{array}$} & \multicolumn{3}{|c|}{ Hybrid Chandler } & \multicolumn{3}{|c|}{ Seed parent 2240} & \multicolumn{3}{|c|}{ Pollen parent 2241} \\
\hline & \multicolumn{2}{|c|}{ Percentages: } & \multirow{2}{*}{$\underset{\text { ratio }}{\mathrm{S}: \mathrm{A} \dagger}$} & \multicolumn{2}{|c|}{ Percentages: } & \multirow{2}{*}{$\begin{array}{l}\mathrm{S}: \mathrm{A} \\
\text { ratio }\end{array}$} & \multicolumn{2}{|c|}{ Percentages: } & \multirow{2}{*}{$\begin{array}{l}\mathrm{S}: A \\
\text { ratio }\end{array}$} \\
\hline & Solids & Acid & & Solids & Acid & & Solids & Acid & \\
\hline 1956-57 & & & & & & & & & \\
\hline Jan. 10 & 14.0 & 1.14 & 12.3 & 12.6 & 0.10 & 126 & 12.0 & 1.53 & 7.8 \\
\hline Feb. $6 \ldots$ & 14.5 & 1.18 & 12.3 & 12.5 & 0.17 & 74 & 12.8 & 1.59 & 8.1 \\
\hline Mar. 7... & 14.0 & 1.21 & 11.6 & 12.6 & 0.14 & 90 & 12.4 & 1.50 & 8.3 \\
\hline \multicolumn{10}{|l|}{$1957-58$} \\
\hline Dec. 13 & 12.0 & 0.98 & 12.2 & 11.7 & 0.08 & 146 & 11.3 & 1.60 & 7.1 \\
\hline Jan. 13 & 12.1 & 0.92 & 13.2 & 12.6 & 0.08 & 158 & 10.8 & 1.59 & 6.8 \\
\hline \multicolumn{10}{|l|}{$1958-59$} \\
\hline Dec. 11 & 12.1 & 0.74 & 16.4 & 12.3 & 0.06 & 205 & 11.7 & 1.04 & 11.3 \\
\hline Jan. 5 . . & 12.0 & 0.78 & 15.4 & 12.3 & 0.10 & 123 & 11.6 & 1.24 & 9.4 \\
\hline Feb. 13... & 12.6 & 0.83 & 15.2 & 13.0 & 0.12 & 108 & 12.1 & 1.26 & 9.6 \\
\hline
\end{tabular}

* Five fruits were regularly used for each sample.

t $\mathrm{S}:$ A means ratio of solids to acid.

Pubescence on leaves and twigs is a characteristic of many pummelo varieties. The parent pummelo 2240 has much fine pubescence on its leaves, twigs, and also on its fruit. Pummelo 2241 has moderate pubescence on leaves and twigs, but practically none on its fruit. The hybrid shows less pubescence on leaves and twigs than either parent, and only a little on the fruit.

The hybrid tree has been vigorous, fast-growing, and fairly open. It has not shown serious thorniness, although the early growth of many citrus varieties is highly thorny after reproduction by seed. With sweet orange rootstock, the bud union after twelve years is smooth and without indication of disease. The variety is now being tried on Cleopatra mandarin and Troyer citrange rootstocks. Long-time bearing behavior and longevity of the tree are not known, nor has its performance been tested in areas other than Riverside.

There is not likely to be a large market demand for pummelos in the 
United States, and therefore Chandler is recommended only for home garden trial or for limited commercial planting as a specialty fruit. It may have a place as a dessert, salad, or breakfast fruit, and may be especially attractive to people of Asiatic extraction, among whom the pummelo is a favorite variety of citrus.

\section{BOTANICAL DESCRIPTION}

Tree vigorous, spreading, moderately open, only slightly thorny. Fruits borne singly or in pairs, well distributed throughout the tree. Leaves large, broad; apex acute; base acute to slightly rounded. Petioles broad, typical of pummelo. Leaves and twigs nearly glabrous, but not completely so.

Fruit ripens at Riverside in December, and is good until February or March-longer if picked and stored. As is characteristic of pummelos, rind does not puff; fruit remains firm until past season. Fruit size similar to large grapefruit, four and one-half to six inches in transverse diameter. Shape good, globose to very deep oblate, with no neck. Radius of fruit cross section often slightly greater on one side than on the other. Rind smooth, except for many small, slightly raised oil glands. Rind surface often slightly pubescent. Stem end slightly rounded, without furrows; blossom end nearly flat, not mammillate; stylar scar about one-eighth inch in diameter. Rind color light yellow, darkening slightly as season progresses. Rind thickness ten to twelve mm., medium for a pummelo (thicker than grapefruit). Albedo adherent to flesh. Rind oil little, odor not prominent.

Core solid, six to ten $\mathrm{mm}$. in diameter, small for a pummelo. Segments usually fourteen to sixteen; segment membranes of medium thickness, moderately tender. Pulp color pale yellow to pale pink, variable within a fruit; yellow similar to Ridgway's plate XVI, Naphthalene Yellow; pink similar to Ridgway's plate XIII, Old Rose, occurring in membranes and albedo. More pink in some years than in others. Pulp texture medium (not coarse); firm but tender. Pulp vesicles medium to large, highly variable in shape. Pulp moderately juicy. Juice pale yellow, similar to Ridgway's plate XVI, Naples Yellow. (Ridgway, 1912.) Juice aroma pleasant but weak.

Level of total soluble solids medium; acid medium to low-medium. Solids : acid ratio moderately high in December and January. Seeds many, typical of pummelo ; large, twelve to fifteen $\mathrm{mm}$. in length ; angular, often near flat, though with well-developed cotyledons. Cotyledons white; outer seed coats cream; inner coats brown.

\section{ACKNOWLEDGMENTS}

Thanks are due Mr. D. A. Cole, Jr., and Mr. R. H. Burnett, of the Department of Horticulture, University of California Citrus Experiment Station, Riverside, for carrying out the fruit composition assays and assisting in other aspects of evaluation of the fruit. 


\section{LITERATURE CITED}

GROFF, G. W.

1927. Culture and varieties of Siamese pummelos as related to introductions into other countries. Lingnan Sci. Jour. 5:187-254.

1930. Culture and varieties of Siamese pummelos. California Citrograph 15:442, 459-62. OCHSE, J. J.

1931. Fruits and fruit culture in the Dutch East Indies (pp. 119-25). G. Kolff and Co., Batavia. $180 \mathrm{pp}$.

REASONER, P. W.

1888. Tropical and semitropical fruits in Florida and the Gulf states. In: Report on the condition of tropical and semitropical fruits. U. S. Dept. Agric. Div. Pomol. Bul. $1: 7-110$.

Reinking, O. A., and G. W. GRofF

1921. The Kao Pan seedless Siamese pummelo and its culture. Philippine Jour. Sci. $19: 389-437$.

RIDGWAY, ROBERT

1912. Color standards and color nomenclature. Published by the author. Washington, D.C.

Soost, R. K., and J. W. CAMEroN

1961. Contrasting effects of acid and nonacid pummelos on the acidity of hybrid citrus progenies. Hilgardia $30(12): 351-57$ (the leading paper in the present issue).

SWINGLE, W. T.

1943. The botany of Citrus and its wild relatives of the orange subfamily. Chapter IV (pp. 129-474) in The Citrus Industry, Vol. I. H. J. Webber and L. D. Batchelor, eds., University of California Press, Berkeley and Los Angeles.

\section{WEBBER, H. J.}

1943. Cultivated varieties of Citrus. Chapter V (pp. 475-668) in The Citrus Industry, Vol. I. H. J. Webber and L. D. Batchelor, eds., University of California Press, Berkeley and Los Angeles.

\section{WESTER, P. J.}

1917. New or noteworthy tropical fruits in the Philippines. Philippine Agric. Rev. $10: 8-23$. 
The journal Hilgardia is published at irregular intervals, in volumes of about 600 pages. The number of issues per volume varies.

Subscriptions are not sold. The periodical is sent as published only to libraries, or to institutions in foreign countries having publications to offer in exchange.

You may obtain a single copy of any issue free, as long as the supply lasts; please request by volume and issue number from:

Agricultural Publications

Room 207 University Hall

2200 University Avenue

Berkeley 4, California

The limit to nonresidents of California is 10 separate issues on a single order. A list of the issues still available will be sent on request. 